\title{
Effects of prenatal stress procedures on maternal corticosterone levels and behavior during gestation
}

\author{
J. M. JOFFE, JAMES A. MULICK, KENNETH F. LEY, JR. \\ and RICHARD A. RAWSON \\ University of Vermont, Burlington, Vermont 05401
}

\begin{abstract}
Exposing pregnant rats to a signal previously paired with electric shock has frequently been used to examine the effects of prenatal stress on their offspring. To determine to what extent this procedure affects the females themselves, their defecation in the shuttlebox and plasma corticosterone levels in their home cages or after shuttlebox exposure were measured. Defecation was significantly more frequent in females that had received premating avoidance conditioning only on the first 2 days of gestation. There were no indications that avoidance conditioning before mating affected plasma corticosterone levels of rats in their home cages or following reexposure to the shuttleboxes or their response to the stress of the first blood sample. Levels were raised in all groups placed in the boxes, whether they had received avoidance conditioning or only CS exposures before mating. Implications for hypotheses concerning the way in which prenatal stress effects are mediated are discussed.
\end{abstract}

Effects of prenatal stress on offspring behavior have been found in a large number of experiments (Archer \& Blackman, 1971; Joffe, 1969) using variations of a technique of stressing pregnant rats introduced by Thompson (1957). The method generally involves training female rats to avoid shock on presentation of a conditioned stimulus (CS) by crossing to the opposite compartment of a shuttlebox. The females are then mated and reintroduced to the shuttlebox daily throughout gestation and exposed to the CS with the avoidance response blocked and no further shock administered. The assumptions behind the use of this technique are that the CS is fear arousing and that blocking the previously learned avoidance response prevents fear reduction or even enhances the level of fear. However, no evidence is available to indicate whether or not the procedure affects the females themselves in any way. In the first experiment, we sought to determine if the procedure affected animals' defecation in the shuttleboxes during gestation or their plasma corticosterone levels after exposure to the situation or in response to routine environmental events. In the second experiment, we sought to assess the effects of premating training alone, since exposing females to avoidance conditioning prior to mating without any further manipulation during gestation has been shown to affect the activity of their

Support by NIH research Grant HD 05571 from the National Institute of Child Health and Human Development, PHS DHEW. We thank John M. Peterson for competent technical assistance and Sue M. Smith for assistance with statistical analyses. offspring (Joffe, 1965) and their "grandpups" (Wehmer, Porter, \& Scales, 1970).

\section{GENERAL METHOD}

\section{Subjects}

Charles River Long-Evans hooded rats were obtained from Canadian Breeding Farms and Laboratories Ltd. Females weighed $168-180 \mathrm{~g}$ on arrival (approximately 63-70 days old), males 250-300 g (about 70 days). Rats were housed in controlled conditions $\left(23 \pm 2^{\circ} \mathrm{C}\right.$; lights on $\left.0600-2000 \mathrm{~h}\right)$.

\section{Apparatus}

Four identical shuttleboxes were used. These are described elsewhere (Joffe, 1977). On conditioning trials the CS, a combination of a 7,000-cps tone and light onset, was followed after $8 \mathrm{sec}$ by the UCS, a scrambled shock $(.5 \mathrm{~mA})$ from a Grason-Stadler shock generator. Crossing within $8 \mathrm{sec}$ of CS onset terminated the CS and enabled the animal to avoid shock. CS-only animals could terminate the CS by crossing to the opposite side of the box. The intertrial interval was 45-105 sec $($ mean $=75 \mathrm{sec})$. A Plexiglas barrier could be placed in the center of the box to prevent an animal from crossing.

\section{Procedure}

Premating avoidance condition (PAC, $\mathrm{N}=60$ ). Each morning for 10 days, each female, in random order each day, was placed in a shuttlebox and received 10 avoidance conditioning trials.

Premating CS-only (PCS, $\mathrm{N}=60$ ). Females received the same training as those in the previous group except that no shock was given at any stage. CS duration was varied each day to insure that the amount of exposure to the CS was the same as in the conditioning groups.

After the 10th day of training, all females, including undisturbed controls, were mated. On Day 1 of gestation, as determined by the presence of sperm in the vaginal smear, PAC and PCS females were randomly assigned to either Experi- 
ment 1 or Experiment 2. Undisturbed females served as the control group (CON) for both experiments, which were run at the same time.

\section{EXPERIMENT 1: EFFECTS OF GESTATIONAL STRESS}

Pregnant females in Groups PAC $(\mathrm{N}=26)$, PCS $(\mathrm{N}=30)$, and CON $(\mathrm{N}=15)$ were randomly scheduled for blood-sampling on Day 3, 12, or 21 of gestation (Day 22 is the expected day of delivery).

\section{Method}

Shuttlebox sessions. Starting on Day 2 of gestation, PAC and PCS females were placed in the shuttlebox each day for a 12-to 14-min session, during which the Plexiglas barrier was in position, preventing the animal from crossing to the opposite side. Each session consisted of a 5-min waiting period followed by five 8-sec CS presentations; no shock was administered during these sessions. The number of fecal boli in the shuttleboxes was recorded each day.

PAC and PCS females received one session each day until the day on which they were blood sampled, at which point they were terminated. CON females, who were not disturbed until the day designated for blood sampling, were also terminated after sampling. That is, the plasma corticosterone measures for different days of gestation were obtained from independent groups of animals.

Blood sampling. Half the animals in Groups PAC and PCS were sampled after their daily shuttlebox session on the designated day of gestation. The remaining half, as well as all CON females, were sampled immediately on removal from their home cages, during the same period that shuttlebox sessions were run $(0900-1100 \mathrm{~h})$. Blood was obtained by jugular venipuncture under ether anesthesia, centrifuged, and the plasma frozen for later assay of corticosterone content (Glick, von Redlich, \& Levine, 1964). One sample was obtained from each rat within $60 \mathrm{sec}$ of removal from the home cage or the shuttlebox (immediate sample), the rat kept in a holding cage, and a second sample was taken 15 min later.

\section{Results}

Shuttlebox defecation. On Day 2 of gestation (the first day of reexposure), avoidance conditioning animals (mean $=2.85 \pm .47)$ defecated significantly more than CS-only animals (mean $=1.38 \pm .39) \quad[\mathrm{t}(57)=2.44$, $\mathrm{p}<.02]$. In addition, more avoidance conditioning animals $(74 \%)$ defecated than CS-only animals (37.5\%) $\left[\left(\chi_{c}^{2}(1)=6.49, p<.02\right]\right.$. On Days 3.11 and 12-20, the groups did not differ significantly on total defecation or in frequency of defecation. The difference is of borderline significance as early as Day 3 of gestation [PAC (mean $=3.17 \pm .64,74 \%$ defecating) vs. PCS (mean $=1.81 \pm .44,48 \%$ defecating); $\mathrm{t}(48)=1.80$, $\mathrm{p}>.05$ (two-tailed test); $\left.\chi_{\mathrm{c}}^{2}=2.45, \mathrm{p}>.10\right]$. Total avoidance was not significantly correlated with shuttlebox defecation on Day 2 of gestation (rho $=.08$ ).

Plasma corticosterone. The significant main effects of sampling upon removal from home cage (HC) vs. following shuttlebox (SB) exposure, day of gestation, and immediate vs. 15 -min sample were qualified by two significant interactions: (1) Post-HC/Post-SB by Immediate $/ 15-\min$ Sample $[\mathrm{F}(1,59)=16.29, \mathrm{p}<.01]$.

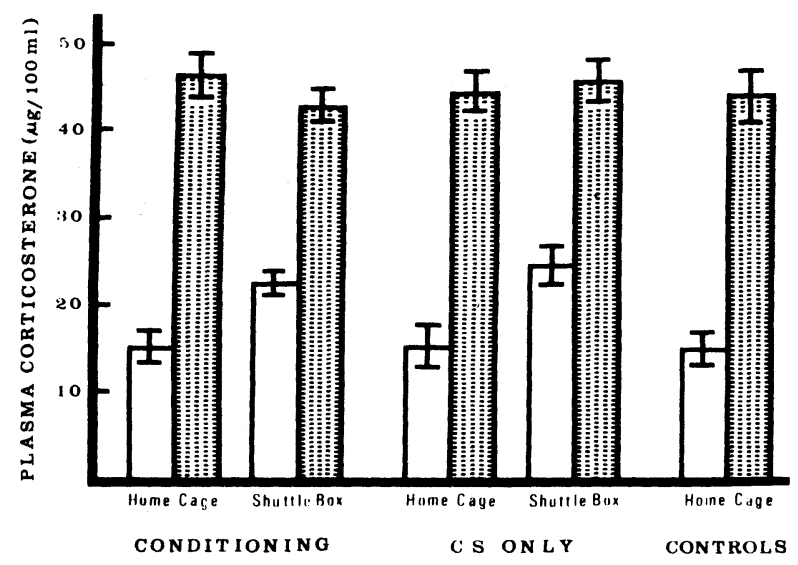

Figure 1. Mean ( \pm SE) plasma corticosterone levels of females that received avoidance conditioning or exposure to the $\mathrm{CS}$ alone prior to mating. Blood samples were taken either on removal from the home cage or after exposure to the shuttlebox. Control females were sampled on removal from the home cage. Open bars represent mean levels for samples taken immediately on removal from cage or shuttlebox, shaded bars mean levels for the second sample, taken $15 \mathrm{~min}$ after the first. $\mathrm{N}=12-15$ per mean.

The means of the groups involved are shown in Figure 1, together with the means of CON animals. Immediate levels were significantly higher following exposure to the shuttlebox than after removal from the home cage $[F(1,58)=20.84, p<.01]$, while the significantly higher levels obtained 15 min later (increased by the stress of the first sampling) were similar in animals sampled after a shuttlebox session and those sampled after removal from the home cage. (2) Day by Immediate $/ 15-\min$ Sample $[F(2,59)=8.38, p<.01]$. There were significant differences in both immediate and 15-min corticosterone levels on different days of gestation. Immediate levels were significantly higher on Day 21 , the day prior to delivery (mean $=24.65 \pm 1.47$, $\mathrm{ug} / 100 \mathrm{ml})$, than on Day 3 (mean $=18.37 \pm 2.46$ ) or Day 12 (mean $=14.88 \pm 1.79$ ). Levels $15 \mathrm{~min}$ after the first sample were, however, depressed in midgestation: Day 12 levels $($ mean $=36.81 \pm 1.08)$ were significantly lower than those on Day 3 (mean $=51.21 \pm 2.12$ ) or Day $21($ mean $=47.32 \pm 1.36)$.

\section{EXPERIMENT 2: EFFECTS OF PREMATING CONDITIONING ONLY}

\section{Method}

Pregnant females from Groups PAC $(\mathrm{N}=14)$ and PCS $(\mathrm{N}=13)$ were randomly scheduled for blood sampling on Days 3,12 , and 21 of gestation. On the designated day, they were blood sampled in the same manner as animals in Experiment 1. The control group was the same as in Experiment 1.

\section{Results}

Significant effects of day of gestation and immediate vs. 15 -min sample were qualified by a significant Day by Immediate $/ 15-$ min interaction $[F(2,33)=4.36, p<.05]$. 
As in Experiment 1, immediate levels were elevated on Day 21 compared to Days 3 or 12, and 15-min levels depressed on Day 12. In addition, there was one significant effect involving premating treatment, the Groups by Day interaction $[F(4,33)=3.35, p<.05]$. There were no differences between groups on Days 3 or 12 of gestation, but on Day 21, PCS animals (mean $=41.30)$ had higher plasma corticosterone levels than PAC $($ mean $=30.36)$ or CON $($ mean $=29.81)$ animals $(\mathrm{ps}<.05)$. The lack of a difference between PAC and CON animals prevents one from concluding that premating avoidance conditioning has depressed corticosterone levels on Day 21 . No other F values involving groups approached significance.

\section{DISCUSSION}

Defecation and plasma corticosterone levels were little affected by premating avoidance conditioning followed by reexposure to the CS during gestation (Experiment 1). Similarly, there is little indication that premating conditioning, either alone (Experiment 2) or in combination with reexposure to the CS during gestation (Experiment 1) results in animals' responding differently, as indicated by plasma corticosterone levels, to general animal colony events during gestation.

Early in gestation, there was significantly more defecation by subjects that had been given avoidance conditioning prior to mating, which appears to indicate that the reexposure to the boxes was more fear arousing for these animals. However, the effect is of short duration, since the difference between the groups was no longer significant as early as the second day of reexposure.

Plasma corticosterone levels indicate even less effect of premating conditioning on animals. Levels were significantly increased by exposure to the shuttlebox, but this was the case for all groups placed in the boxes, whether they had received avoidance conditioning or merely exposure to the CS before mating. Nor did the premating procedures differentially affect an animal's response to the stress of the first blood sample. There was, then, an adrenocortical response to the handlingCS-shuttlebox situation, but it was not differentially affected by the procedures to which the rat had been exposed prior to mating. A similar picture is obtained from the plasma corticosterone levels of the various groups that were blood sampled immediately after removal from their home cages. Neither the CS-exposure procedure (Experiment 1) nor premating conditioning alone (Experiment 2 ) produced differences in plasma corticosterone in response to general animal colony events or to the stress of the first blood sample. The single significant effect, the raised corticosterone level in PCS animals on Day 21 (Experiment 2). involves a procedure included here as a control condition which has not been used in experiments on the effects of prenatal stress or premating conditioning on offspring behavior.

Both analyses of plasma corticosterone levels revealed changes over the course of gestation. Levels in animals sampled immediately on removal from the home cage were similar on Days 3 and 12, but significantly elevated on Day 21 of gestation (the day prior to parturition) and the adrenocortical response to the stress of blood sampling was significantly depressed in midgestation. The former findings are in accord with earlier reports (Kamoun, 1970a; Ota, Ota, \& Yokoyama, 1974). Kamoun (1970b) also reported that stress levels of plasma corticosterone are not significantly higher toward the end of pregnancy than they are in nonpregnant controls. Previous investigators have not examined the effects of stress on plasma corticosterone levels in midgestation. The present data indicate clearly that, for reasons that are currently obscure, the maternal pituitary-adrenocortical system is relatively unresponsive to intense stress at midpregnancy.

The short duration of the effect of premating conditioning on defecation in the shuttleboxes during gestation and the lack of effects on plasma corticosterone levels raise questions about the mediation of prenatal stress effects. Procedures similar to those used in the present experiments have been found to affect the behavior of offspring either when premating conditioning alone was used (Joffe, 1965; Wehmer et al., 1970) or when both premating conditioning and exposure to the CS during gestation were used (Archer \& Blackman, 1971; Joffe, 1969). This suggests that the effects of the procedure (conditioning plus reexposure to the shuttlebox during gestation) are due to incidental events (handling, CS, exposure to the box) rather than to the conditioning procedure and the reexposure to the "fear-arousing" stimuli. Handling rats during gestation has been found to affect the behavior of their offspring (Ader \& Conklin, 1963; Ader \& Plaut, 1968), but offspring open-field activity, the measure most frequently reported to be affected by prenatal conditioning procedures, was not affected (Ader \& Conklin, 1963). In addition, the effects of the CS-xposure procedure have been found to differ from those of prenatal handling (Hockman, 1961; Morra, 1965a, 1965b), and differences in the effects of CS-xposure procedures have been reported to result from variations in the number of avoidance training and reexposure trials and the number of shocks (Thompson \& Quinby, 1964 ) or in the number of avoidance trials alone (Morra, 1965b). In experiments such as the latter two, incidental variables are similar in all groups and, consequently, differences in the effects due to manipulations of conditioning parameters argue against the effects being due to the incidental variables.

An alternative to supposing that the major relevant aspect of CS-exposure procedures is the attendant handling, and so on, is to suppose that the effects of CS-exposure procedures are not mediated primarily by activation of the pituitary-adrenocortical system. Since only a sample of the rats' adrenocortical response to reexposure to the shuttlebox was obtained, it is possible that plasma corticosterone levels may have differed at a different time of day, on a different day of pregnancy, or at a different period after removal from their cage. However, when viewed in conjunction with findings showing that effects of prenatal stress procedures on offspring behavior are obtained even when the maternal pituitary-adrenocortical system is inactivated (Joffe, 1977; Smith, Joffe, \& Heseltine, 1975), the present data suggest that prenatal stress effects on offspring behavior do not require involvement of the maternal pituitary-adrenocortical system. It would appear to be advisable for experimenters to monitor additional systems in studies designed to elucidate the mechanisms underlying the effects of prenatal stress on offspring behavior.

\section{REFERENCES}

Ader, R., \& ConkıIN, P. M. Handling of pregnant rats: Effects on emotionality of their offspring. Science, 1963, 142, 411-412.

Ader, R., \& Plaut, S. M. Effects of prenatal maternal handling and differential housing on offspring emotionality, plasma corticosterone levels, and susceptibility to gastric erosions. Psychosomatic Medicine, 1968, 30, 277-286.

Archer, J. E., \& Blackman, D. E. Prenatal psychological stress and offspring behavior in rats and mice. Developmental Psychobiology, 1971, 4, 193-248.

Glick, D., von Redicich, D., \& Levine, S. Fluorometric determination of corticosterone and cortisol in 0.02-0.05 milliliters of plasma or submilligram samples of adrenal tissue. Endocrinology, 1964, 74, 653-655.

Hockman, C. H. Prenatal maternal stress in the rat: Its effects on emotional behavior in the offspring. Journal of 
Comparative and Physiological Psychology, 1961, 54, 679-684.

JoFFE, J. M. Genotype and prenatal and premating stress interact to affect adult behavior in rats. Science, 1965, 150, 1844-1845.

Joffe, J. M. Prenatal determinants of behavior. Oxford, Pergamon, 1969.

JoFFE, J. M. Modification of prenatal stress effects in rats by dexamethasone and adrenocorticotrophin. Physiology and Behavior, 1977, 19, 601-606.

Kamoun, A. Activité cortico-surrénale au cours de la gestation, de la lactation et du développement pré et post-natal chez le rat. I. Concentration et cinétique de disparition de la corticosterone. Journal of Physiology, Paris, 1970, 62, 5-32. (a)

Kamoun, A. Activité cortico-surrénale au cours de la gestation, de la lactation et du développement pré et post-natal chez le rat. II. Régulation de l'activité corticotrope hypophysaire dans les conditions normales et au course de l'aggression. Journal of Physiology, Paris, 1970, 62, 33-50. (b)

MoRRA, M. Levels of maternal stress during two pregnancy periods on rat offspring behavior. Psychonomic Science, $1965,3,7-8$. (a)
MorRA, M. Prenatal sound stimulation on postnatal rat offspring open field behaviors. Psychological Record, 1965, 15, 571-575. (b)

Ota, K., Ота, T., \& Yокочама, A. Plasma corticosterone concentrations and pituitary prolactin content in late pregnancy and their within-day fluctuations in the rat. Journal of Endocrinology, 1974, 61, 21-28.

Smith, D. J., Joffe, J. M., \& Heseltine, G. F. D. Modification of prenatal stress effects in rats by adrenalectomy, dexamethasone and chlorpromazine. Physiology and Behavior, 1975, 15, 461-470.

Thомpson, W. R. Influence of prenatal maternal anxiety and emotionality in young rats. Science, 1957, 125, 698-699.

Thompson, W. R., \& Qunni, S. Prenatal maternal anxiety and offspring behavior; prenatal activity and level of anxiety. Journal of Genetic Psychology, 1964, 106, 359-371.

Wehmer, F., Porter, R., \& Scales, B. Prenatal and pregnancy stress in rats affects behavior of grandpups. Nature, 1970, 227, 622.

(Received for publication October 24, 1977.) 